\title{
Frontiers in Molecular Evolutionary Medicine
}

\author{
Stephen C. Stearns ${ }^{1} \mathbb{D}$
}

Received: 26 February 2019 / Accepted: 29 March 2019 / Published online: 9 April 2019

(c) Springer Science+Business Media, LLC, part of Springer Nature 2019

\begin{abstract}
This paper surveys some of the important insights that molecular evolution has contributed to evolutionary medicine; they include phage therapy, cancer biology, helminth manipulation of the host immune system, quality control of gametes, and pathogen outbreaks. Molecular evolution has helped to revolutionize our understanding of cancer, of autoimmune disease, and of the origin, spread, and pathogenesis of emerging diseases, where it has suggested new therapies, illuminated mechanisms, and revealed historical processes: all have practical therapeutic implications. While much has been accomplished, much remains to be done.
\end{abstract}

Keywords Evolutionary medicine $\cdot$ Phage therapy $\cdot$ Cancer $\cdot$ Autoimmune disease $\cdot$ Emerging diseases

\section{Introduction}

Evolutionary medicine, an increasingly well recognized area of basic research and medical practice, is supported by a growing literature to which this issue of Journal of Molecular Evolution now contributes. It consists of all points at which evolutionary approaches shed useful light on medical topics. To introduce it, I focus on exciting recent advances that offer opportunities for those interested in and skilled at the analysis of molecular evolution. Those advances include insights into phage therapy, cancer biology, host-parasite interactions, reproductive biology, and pathogen outbreaks. In discussing them, I have not aimed for scholarly reviews that cover all major contributions: space is too limited, recent reviews of each are available elsewhere, and such treatment could bore the reader. Instead I have chosen topics I find exciting using recent references that provide entry to the rapidly expanding literature. Those seeking a broader introduction might sample Evolutionary Medicine (Stearns and Medzhitov 2015).

Handling Editor: Konstantinos Voskarides.

Stephen C. Stearns

stephen.stearns@yale.edu

1 Department of Ecology and Evolutionary Biology, Yale University, PO Box 208106, New Haven, CT 06520-8106, USA

\section{Phage Therapy}

Although initially developed early in the twentieth century before the discovery and widespread use of antibiotics, phage therapy has re-emerged as one key element in the response to the widespread evolution of antibiotic resistance in many bacterial pathogens. It is becoming the therapy of choice in cases where bacterial strains that resist all available antibiotics threaten critically ill patients with hospital-acquired infections. Phage do not attack the eukaryotic cells of patients, nor do they induce anaphylaxis, but they do elicit the production of anti-phage antibodies that can dampen their impact without necessarily resulting in treatment failure. Following a long history of success in humans in Eastern Europe, particularly in Poland and Georgia, and recent demonstrations of efficacy in animal models, phage therapy has succeeded in treating two cases of Pseudomonas aeruginosa infections in Belgium and the US and is currently the focus of a large scale trial in France, Belgium, and Switzerland that aims to prevent burn infections (Kakasis and Panitsa 2019).

\section{Clinical Success and Failure}

Phage therapy had short-lived success for a patient in Belgium who had acquired a $P$. aeruginosa infection after developing necrotic pressure sores during the extended hospitalization that followed bowel surgery (Jennes et al. 2017). When antibiotic therapy was discontinued to limit kidney 
damage, septicemia caused by $P$. aeruginosa emerged, and the patient went into a coma. With emergency clearance from administrative authorities, a $50 \mathrm{ml}$ purified phage cocktail was then administered intravenously for $6 \mathrm{~h}$ each day for 10 days at the same time that the wounds were directly irrigated with the same cocktail every $8 \mathrm{~h}$ for 10 days. Improvement was dramatic: blood cultures turned negative almost immediately, temperature returned to normal in about 2 days, and blood tests used to assess infections returned to normal range within a week. Unfortunately, the patient died 4 months later in the hospital from heart failure mediated by sepsis caused by Klebsiella.

The outcome was happier for a patient in Connecticut with a chronic, multiple-resistant $P$. aeruginosa infection in an aortic Dacron graft (Chan et al. 2018). In this case, the therapeutic team chose a clever strategy: they selected a phage that targeted the efflux pump that endowed the bacterium with antibiotic resistance, and they followed the phage treatment, which knocked out the efflux pump, with an antibiotic treatment. The infection resolved and did not recur. That team has gone on to treat seven more cases (Chan pers. comm.), five with cystic fibrosis (CF) and two with non-CF bronchiectasis, a type of COPD in which the bronchi are damaged, mucus accumulates, and bacteria grow in the accumulated mucus. Those seven cases were treated by inhaling an aerosol. In all seven improvement was observed; in one case of non-CF bronchiectasis the lung infection was eradicated. Two more cases of CF with multiple-resistant bacterial infections are currently being treated.

A Phase 1 trial of phage therapy for burn victims with $P$. aeruginosa infections in France and Belgium did not reduce bacterial burden as rapidly as did the standard of care to which it was compared, a sulfadiazine cream (Jault et al. 2019). In this case the concentration of phage was lower than planned and not specifically selected to disable an efflux pump; the bacteria were subsequently shown to be resistant to such low doses of phage; they were also susceptible to the antibiotic in the comparison treatment. Phage therapy does not always succeed; success takes both careful planning and appropriate targets; and it is currently best deployed against infections caused by multiple-resistant bacteria.

\section{Research Priorities}

Bacteria have evolved defenses against phage; the most famous is CRISPR, but there are others. Current best practice involves a preliminary stage in which a phage library is screened to identify strains effective against specific bacteria. Not all bacteria are equally susceptible to phage attack, and many bacteria could evolve defenses in reaction to phage therapy. Thus, one research priority is to identify molecular markers in phage and bacteria that signal capacities for attack and resistance, test the top candidates in vitro, then in animal models, followed by Phase 1 trials in humans, and thereby develop a reliable overview of when phage therapy should be used and when it should not.

A second research priority is to investigate whether phage can safely be deployed in the human gut without compromising the function of essential microbiota. Oral administration would open up a range of recalcitrant infections to phage therapy, but a potential serious side effect could be the elimination of beneficial bacteria from the gut microbiota. Detailed molecular detective work will be required to explore the balance of costs and benefits.

A third research priority is to conduct large-scale molecular screens aimed at matching the natural diversity of phage, which is largely unexplored, with the natural susceptibilities of pathogenic bacteria. It could produce an open access data bank of therapeutic options that might indicate which should be tried first.

\section{Cancer Biology}

When clean water supplies, improved nutrition, antibiotics, and vaccinations caused infectious disease to drop as a leading cause of mortality in developed countries, mortality rates decreased, causing a major demographic shift. Many more people survived to older ages, and in that older group non-infectious causes of death, emerging from the selection shadow of our previously shorter lifespans, became increasingly important. Prominent among those causes are heart disease, dementia, and cancer (Corbett et al. 2018).

Every cancer is a case of clonal evolution, and one major cancer treatment, chemotherapy, elicits the evolution of resistance among competing clones that is just as rapid and dramatic as that of antibiotic resistance. Chemotherapy kills susceptible clones and favors the resistant clones that come to dominate the set of metastases that kill the patient when treatment fails. How to manage chemotherapy to slow that evolutionary response is the first subject of this section on cancer biology.

But why are we at risk of metastatic cancer in the first place? Is it a relatively recently evolved result of a superficial change, or is it more deeply rooted in our biology? Part of the answer lies in the surprising connection between the invasiveness of placentas and the risk of metastases, the second subject of this section.

Can we identify genetic vulnerabilities unique to cancer cells that are not shared by the normal cells from which they are derived and exploit those vulnerabilities for targeted therapies that kill cancer cells and leave normal cells unharmed? Here, the evolutionary history of gene duplications that has produced functional paralogs can help in locating appropriate targets, the third subject of this section. 
Are we at increased risk of cancer in old age because it is in part the byproduct of alleles that increase fitness earlier in life via their impacts on juvenile survival, fecundity, or lifetime reproductive success through antagonistic pleiotropy? We now have some direct molecular evidence that such effects do exist, the fourth subject of this section.

When did a cancer originate, and what was the sequence of mutations that marked its emergence as a threat? When multiple metastases are harvested from a single patient, sequencing them allows us to reconstruct their phylogenetic history. This application of molecular phylogenetics, which has become increasingly common, has yielded some surprising insights. Some of those insights lend hope for improved detection and therapy, the fifth subject of this section.

\section{Adaptive Therapy}

The sets of clones that constitute a tumor evolve in response to chemotherapy. Attempts to target specific molecular mechanisms of resistance have had little success because of the diverse mechanisms present among the genetically differing clones. Chemotherapy aimed at one mechanism simply allows cells using other mechanisms to increase. Treating with maximum doses also hastens the expansion of resistant clones by reducing competition with susceptible clones. These insights were initially explored in models that showed that patient survival could be increased by modulating chemotherapy to maintain a stable population of sensitive clones that can suppress resistant clones in the absence of chemotherapy (Gatenby et al. 2009), a result later confirmed by modeling the specific case of castrate-resistant prostate cancer (Cunningham et al. 2018). This approach, called adaptive therapy, can only be done safely with cancers whose growth can be followed with imaging or other methods, for it is essential to know when the tumor burden has been stabilized. A key insight is that although the evolution of resistance to every currently available therapy is inevitable, the expansion of resistant cells is not: it can be delayed, perhaps indefinitely, with interventions based on understanding clonal dynamics (Gatenby and Brown 2018). With proof-of-principle now demonstrated in model systems that include mice (Gatenby et al. 2009) and cultures of human breast cancer cells (Silva et al. 2012), the approach has moved into a Phase 1 clinical trial (Gatenby pers. comm.).

\section{The Connection Between Invasive Placentas and Metastasis}

The idea that placentation and metastasis might be related was initially prompted by the casual observation that species with less invasive placentas, such as ungulates, have fewer metastatic cancers and more solid tumors than do species with more invasive placentas, such as carnivores and primates. Because every cell in the body contains all the genetic information needed to carry out the functions of all cells at all stages of life, it would make sense that organisms with cells that can invade the endometrium during implantation would contain adult cells that could reactivate those capacities as metastatic cells capable of moving among tissues and establishing themselves in new environments. Molecular evidence indicates that the same genetic networks are deployed in placental and in cancer cells (Ferretti et al. 2007). The phylogenetic evidence suggests that invasion was the ancestral state in Eutheria. Invasion involves two actors: fetal cells invade, and maternal cells resist. The comparative evidence suggests that the ancestral state, fetal invasion, was countered by maternal resistance that was stronger in ungulates than in carnivores (D'Souza and Wagner 2014).

The role played by evolved changes in maternal resistance recently received experimental support in a study of the invasion of human and bovine cancer and placental cells into lawns of bovine and human endometrial cells and skin fibroblasts. Both types of bovine cells were more resistant to invasion than were either type of human cells. Moreover, genes with higher expression in human than in bovine fibroblasts were identified, and when they were knocked down in human fibroblasts, those cells resisted invasion significantly more strongly. This work suggests that the permissiveness of stromal tissue to invasion is a single character involved in both the invasion of the endometrium by fetal cells and the invasion of various tissues by metastatic cells (Gupta et al. 2019). Thus, the study of stromal invasibility could lead to anti-metastatic therapies.

\section{Exploiting Paralogs: Synthetic Lethals}

Synthetic lethality exists when mutation in either of two different genes has no effect but mutations in both cause cell death. The effect arises when the two genes function in redundant or cooperating pathways. The therapeutic opportunity arises when a mutation in one of the genes is identified as specific to a cancer; blocking the expression of the other gene will then kill cancer cells but not normal cells (Ashworth 2008). This approach has been successful in treating patients whose cancers are associated with germline mutations in BRCA1 or BRCA2, which increase the risk of breast, ovarian, pancreatic, and prostate cancer (Ashworth and Lord 2018). The evolutionary twist comes from noting that many pairs of synthetic lethals are functionally redundant paralogs. One research opportunity for those with skills in molecular evolution is the efficient identification of paralog synthetic lethal pairs in platforms tailored for genomic analysis of cancers; this would enable a broader range of individualized therapies (Hu pers. comm.). The payoff for molecular evolution in general would 
come from deeper understanding of how both copies of duplicated genes retain function.

\section{Direct Molecular Evidence for Antagonistic Pleiotropy}

Germline mutations in the BRCA1 and BRCA2 genes appear to be maintained in modern populations because of their fertility benefits (Smith et al. 2011), and the p53 allele that improves blastocyst implantation and reduces infertility also decreases lifespan, with an associated increased risk of a variety of cancers (Kang et al. 2009). Molecular sleuthing has also suggested significant associations between cancer risk and genetic adaptations to cold and to high altitude (Voskarides 2018). It can be expected to uncover many more such associations.

\section{Molecular Phylogenetics of Metastases}

Once detected, pancreatic cancer is notorious for the speed with which it kills-20\% survive 1 year. That fact gave special force to the results of one of the first phylogenetic analyses of metastases. It compared metastases from pancreatic cancers in seven individuals, finding that a decade elapsed between the initiating mutation and the birth of the non-metastatic founder cell and that at least five more years elapsed before metastasis began, after which patients died within an average of another 2 years (Yachida et al. 2010). The insight that oncologists had a much longer time than had been thought in which to detect such a cancer helped to motivate the many subsequent phylogenetic analyses of metastases. One issue that such studies seek to resolve is whether metastases spread from metastasis to metastasis or as parallel metastases from a primary tumor. Simply observing the monophyly of metastases does not distinguish between those options; doing so requires ultra-deep sequencing to identify the complete phylogeny of clones within the primary tumor (Hong et al. 2015). A later study demonstrated that in fact metastases can originate from different lineages within the primary tumor; confirmed that metastatic lineages arise early within primary tumors, often long before diagnosis, focusing attention on identifying driver mutations that originate early; and showed that the sequence in which driver mutations arise can be inferred from the phylogeny, thus informing strategies for targeted therapies (Zhao et al. 2016). It is clear that the harvest of insights into cancer biology from molecular phylogenetics has been fruitful (Naxerova and Jain 2015) and is not yet complete.

\section{Helminths, Hygiene, and Mismatch}

\section{Rationale}

The Hygiene Hypothesis posits that autoimmune diseases increased in prevalence when civilization cleaned up the environment and suppressed infectious disease. Two patterns stimulated it. The first was the temporal correlation, in developed countries, between a striking increase in the incidence of autoimmune diseases and the decrease in infectious diseases in the twentieth century. The second was the lack of autoimmune diseases in tropical countries in which helminth infections are widespread. Those two patterns, one in time, the other in space, suggested the idea that cleaning up our environment had the unintended side effect of perturbing our microbiota so seriously that immune pathologies resulted. Initially, helminths were the prime suspect, for their life histories suggest that they should have highly developed capacities to manipulate the immune responses of their hosts. Helminths suffer huge mortality losses in transmission among hosts, losses that can only be balanced by long persistence and high fecundity once established in a host, functions greatly aided by ability to manipulate the host immune system. Other pathogens, parasites, and symbionts have also experienced major challenges as their human hosts acquired them and then domesticated themselves via the agricultural, industrial, and epidemiological revolutions, a series of rapid cultural changes that have left our biology in general and our microbiota in particular mismatched to our current environment (Rook 2012). If removing an element of our microbiota, such as helminths, results in immune pathologies, then identifying what helminths are doing when they are present should yield clues to therapies for autoimmune diseases that include Type I diabetes, the various irritable bowel syndromes (Crohn's disease, ulcerative colitis, and celiac disease), multiple sclerosis, allergies, asthma, and others. Such therapies are sorely needed, for up until now, physicians have usually only been able to treat the symptoms, not the causes, of autoimmune diseases, most of which cause great suffering. Some can kill.

\section{Helminth Manipulation of the Immune System}

Helminths interact directly with their host by producing proteins, glycans, and exosomes containing miRNAs, and they interact indirectly by promoting the growth of bacteria that produce the short chain fatty acids that maintain populations of immune cells, including Tregs (Coakley et al. 2016). Some of these helminth products interact with the molecules used to coordinate communication within 
the immune system, such as interleukins and cytokines. Helminths that live in the gut use these pathways to suppress inflammatory responses; they are a particular source of inspiration for potential therapies for the inflammatory bowel diseases (Varyani et al. 2017). Attempts to use live worms or cocktails of worm eggs as therapies have had mixed results, prompting attention to shift to developing worm-inspired drugs that can be administered in controlled doses.

\section{Implications for Drug Development}

The list of molecules excreted or secreted (E/S) by helminths is long and contains many proteins. Proteins make problematic drugs because they are antigens that elicit immune responses. Worm-inspired drug-development, therefore, focuses on low-molecular weight E/S components and on artificial small molecules that mimic the active sites of proteins (Kahl et al. 2018). Advances in proteomics and the development of bioreactor modules, such as human gut-ona-chip models, have accelerated progress, but potential drugs are not yet in clinical trials.

A comprehensive understanding of the coevolution of the molecular interactions between helminths and hosts would provide many insights to guide the development of therapies for these increasing prevalent and difficult-to-treat diseases of civilization.

\section{Menopause and Atresia}

Mammalian eggs and sperm differ dramatically in their biology. In human females, the ovaries form in the fetus in the third month and are stocked with about 7 million primary oocytes that are arrested in prophase I of meiosis. The process of oocytic atresia then starts to decrease that number. Roughly a million are left at birth, a few thousand when a young woman starts to menstruate at menarche, when oocytes start to be recruited for ovulation (Kerr et al. 2013). The process continues at a less dramatic pace until the number of follicles drops below the endocrine threshold needed to sustain ovulation and menstruation and the woman enters menopause. Thus, women start with a finite number of primary oocytes and steadily lose them (some replacement may be possible Kerr et al. 2013) until they run out. In contrast, sperm are not produced in the testes until puberty. Spermatogonia then continue to undergo mitosis and meiosis throughout life, producing millions of sperm per day. When the concentration of male sex hormones starts to decline between the ages of 40 and 60 , sperm production decreases, but it usually only ceases completely with death.

The most striking genetic difference between oocytes and sperm is the number of mitoses between initial formation of the gonad and production of the gamete: very few in oocytes, hundreds in sperm. Because each mitosis is an opportunity for mutation, this difference in developmental history helps to explain why the number of mutations entering the human population through men is roughly five times the number that enter through women and why those contributed by men increase in frequency with the age of the father (Crow 2000a, b, 2012).

Female mammals invest more time and energy in offspring than do males; they could therefore be expected to have evolved more sophisticated methods of quality control of their offspring than have males (Kozlowski and Stearns 1989). Only allowing their oocytes a minimal opportunity to mutate is the first and most basic feature of this quality control.

\section{The Quality Control Hypothesis}

Because controlling the quality of the oocytes that are fertilized, implant, and become fetuses should be a top priority in the evolutionary design of the female reproductive tract, it was suggested that oocytic atresia functions to eliminate genetically defective oocytes (Stearns and Ebert 2001). The mechanisms involved are being discovered: one is DNAdamage-induced apoptosis of resting oocytes mediated by p63, a member of the p53 family (Tuppi et al. 2018). Oocyte death can also be triggered by defects in the synapsis and recombination of chromosomes during meiosis that produce double strand breaks, which also induce apoptosis (Qiao et al. 2018). While we know that many defective oocytes are eliminated, and some of the mechanisms involved, we do not yet have good estimates of the average quality of a random oocyte selected at each age of a random female's life, and thus, especially given the possibility of some replacement, cannot yet provide a reliable answer to the question, Does oocytic atresia improve egg quality? There is some evidence that quality control deteriorates with age: the percentage of trisomies in recognized pregnancies increases from 2 to $3 \%$ at ages $15-25$ to $25-35 \%$ at ages 40 and over, with a striking acceleration in incidence starting at ages 32-33 (Crow 2000b). Does atresia reduce the rate at which damage increases with maternal age? Clearly there are intriguing research opportunities with significant therapeutic implications in the age-related molecular population genetics of oocytes and in the study of the age-related mechanisms that mediate their quality. We need direct molecular evidence for or against the idea that the genetic quality of eggs is improved by atresia.

\section{Menopause: Contrasting Hypotheses}

Humans are the only primate in which there is menopause followed by a significant period of post-reproductive 
survival. Why should any organism not reproduce until it dies? This striking question has stimulated several hypotheses on why menopause evolved. One, the Grandmother Hypothesis, sees menopause as an adaptation that allows an aged female to gain more fitness by helping her offspring rear grandchildren than she would by having another child herself at an age when she might not be able to care for it properly until it was independent (Hawkes et al. 1998). The Grandmother Hypothesis has stimulated a substantial literature; while there is some support, overall evidence is mixed (e.g. Strassmann and Garrard 2011). A second hypothesis views menopause not as an adaptation but as a byproduct of quality control, the end result of finally running out of oocytes subject to continual atresia (Stearns and Ebert 2001). A third hypothesis combines the first two, viewing the postreproductive lifespan of human females as a consequence of decreased mortality rates (self-domestication) that allow them to survive to ages at which they run out of oocytes that are being filtered for quality control, at which point evolution then makes use of the presence of older females by adapting their behavior to grand-mothering (Ellison and Ottinger 2014). Other possible causes include impacts on females mediated by intra-locus cross-sex effects that originate in selection on males, whose reproductive ability continues to greater ages than does that of females (Stearns et al. 2012). While investigating the molecular population biology of oocytes and the age-dependent mechanisms that control their quality will not by itself discriminate among these hypotheses-that will require case-control studies of lifetime reproductive success-it will provide relevant information that will advance the discussion and constrain the range of plausible ideas.

\section{Pathogen Outbreaks}

The molecular phylogenetic study of the ancestral hosts and post-emergence evolution of human pathogens has been a rich field of inquiry for several decades. By providing increasingly accurate answers to key questions-Where did they come from? How do their animal hosts tolerate them? And how have they changed as they adapt to humans?these studies have yielded basic insights that support both prevention and treatment. Because the literature is large and many reviews are available, I here discuss only a few striking insights into the recent evolution of a few important pathogens.

\section{Cholera in Yemen}

The current epidemic of cholera in Yemen has produced more than a million suspected cases and caused more than two thousands deaths (Al-Mekhlafi 2018). Molecular phylogenetics has revealed that the cholera lineage that emerged in Yemen originated in South Asia and had earlier caused outbreaks in East Africa. Importantly, that lineage is susceptible to several antibiotics used to treat cholera (Weill et al. 2019), a critical piece of evidence that lends confidence to a strategy that deploys those antibiotics without serious concern that genetic variation for resistance will soon destroy their efficacy.

\section{Tuberculosis}

Tuberculosis causes more human deaths than any other infectious disease. While it had originally been thought that humans acquired TB from domestic animals in the Neolithic, whole-genome analyses now suggest that humans transmitted TB to their livestock after a period in which multiple host-jumps may have occurred among humans and wild animals. Estimates of the time at which TB entered humans range from 70,000 to 6000 years, a striking degree of uncertainty that could be resolved by analyzing more ancient Mycobacterium genomes. Phylogenomics has provided useful insights into the evolution and geographic distribution of drug resistance (Gagneux 2018). Interestingly TB appears to have entered Native American populations prior to European colonization via transmission from seals or sea lions, which may have carried it across the oceans before the European voyagers crossed the Atlantic and Pacific (Bos et al. 2014).

\section{Ebola}

The Ebola virus was first identified in 1976 as the causative agent of an outbreak in Kikwit in what was then Zaire. That has been followed by 14 outbreaks, the largest of which occurred in Guinea, Liberia, and Sierra Leone in 2013-2016; the most recent continues at this writing in northeastern Democratic Republic of Congo. The case fatality rate has ranged from 47 to $89 \%$, and the basic reproductive number $R_{\mathrm{o}}$ - the number of new cases originating by transmission from a patient-has been 1.5 to 2.5. Ebola is a strikingly deadly, moderately transmissible disease. The first case in the recent West African outbreak, which caused 28,646 cases and 11,323 deaths (Dudas et al. 2017), occurred in late December 2013 in Guinea, to which it appears to have moved fairly recently from Central Africa (Holmes et al. 2016). Molecular phylogeography, practically in real time, has allowed detailed reconstruction of its origin and spread, knowledge that will be quite helpful in dealing with future outbreaks (Dudas et al. 2017).

\section{Influenza}

The influenza pandemic of 1918-1920 infected about 500 million people, killing about 50 million. It appears to have 
originated shortly before 1918 when a human H1 (hemagglutinin variant 1) virus recombined with an avian N1 (neuraminidase variant 1) virus (Worobey et al. 2014). It then emerged at a geographical location that has not yet been located, spreading simultaneously across Europe, Asia, and North America (Taubenberger and Morens 2006). The recovery and sequencing of additional intact viral genomes will further illuminate the origin and spread of this recent great pandemic, a repeat performance of which would be catastrophic.

\section{HIV}

Human immunodeficiency virus (HIV) has been the subject of intense phylogenetic and phylogeographic scrutiny. Chimpanzees were the original hosts of HIV-1, which is the major cause of acquired immune deficiency syndrome (AIDS). It is pathogenic in chimpanzees. Four lineages of HIV-1 have jumped into humans; one or two of those transmissions may have been via gorillas. Their close relatives are simian immunodeficiency viruses (SIVs), which infect more than 40 species of monkeys without apparent pathogenesis. The virus lineage that has caused the AIDS pandemic probably entered humans in the extreme southeast corner of Cameroon (Sharp and Hahn 2010) when a hunter butchered an ape. Detailed study of HIV-1 genomes isolated from 1970s samples has shown that the virus was circulating in North America in the early 1970s, where it arrived in New York City from the Caribbean (Worobey et al. 2016).

\section{Zika}

Zika, which was isolated from primates in Uganda in 1947, is a mosquito-borne flavivirus whose human infections, mostly in Africa and Asia, were formerly thought to be sporadic, mild, and self-limiting. In 2007 it emerged on Yap Island in Micronesia with 49 confirmed cases, infecting about $75 \%$ of the population (many cases are asymptomatic); the next outbreak, with 396 cases and about 29,000 people infected, was in 2013 in French Polynesia, where more than 40 cases were linked to Guillain-Barré syndrome, a severe neuropathological autoimmune disease. Phylogenetic analyses indicate that it arrived in Brazil in 2013, where it quickly spread. By the end of 2016 it had appeared in at least 48 countries and territories in the Americas and was linked to microcephalic birth defects. During its expansion it acquired particular amino acid substitutions in the same lineages in which birth defects were detected; those substitutions, combined with reverse genetics in model organisms, are providing clues to its transmission and pathogenesis (Liu et al. 2019).

\section{Why Bats?}

Molecular phylogenetics has established that bats are the reservoirs of many of the most dangerous emerging viral diseases, including Rabies, Ebola, Marburg, Hendra, Nipah, severe acute respiratory syndrome (SARS), and Middle East respiratory syndrome (MERS; Cui et al. 2019). How do bats tolerate viruses that are so virulent in humans? Several answers have been proposed. Bats have idiosyncratic immune responses restricted to specific viral infections for which they have long evolutionary experience, avoiding immunopathology via tolerance. Their daily flight and torpor, and the seasonal hibernation of some species, produce large variations in temperature and metabolic rate associated with evolved differences in the mechanisms that mediate oxidative stress. Those mechanisms, which manage reactive oxygen species, both allow them to live long lives despite expending about twice as much energy per lifetime as nonvolant mammals of comparable size and may help them to tolerate viral infections (Brook and Dobson 2015). Clearly clues to treating some of the most virulent diseases known to man could be found in the tolerance mechanisms that bats have evolved.

\section{Conclusion}

Information on molecular evolution has contributed decisively to some of the most exciting insights of evolutionary medicine: phage therapy, cancer biology, parasite manipulations of the immune system, human reproductive biology, and pathogen outbreaks. Its contributions are far from exhausted; your attention is invited.

Acknowledgements I thank Kevin Hu for insights into synthetic lethals, Ben Chan and Paul Turner for conversations about phage therapy, and Alaric D'Souza and Gunter Wagner for conversations about placental invasiveness and metastatic cancer.

\section{References}

Al-Mekhlafi HM (2018) Yemen in a time of cholera: current situation and challenges. Am J Trop Med Hyg 98:1558

Ashworth A (2008) A synthetic lethal therapeutic approach: poly(ADP) ribose polymerase inhibitors for the treatment of cancers deficient in DNA double-strand break repair. J Clin Oncol Off J Am Soc Clin Oncol 26:3785

Ashworth A, Lord CJ (2018) Synthetic lethal therapies for cancer: what's next after PARP inhibitors? Nat Rev Clin Oncol 15:564

Bos KI, Harkins KM, Herbig A, Coscolla M, Weber N, Comas I, Forrest SA, Bryant JM, Harris SR, Schuenemann VJ, Campbell TJ, Majander K, Wilbur AK, Guichon RA, Wolfe Steadman DL, Cook DC, Niemann S, Behr MA, Zumarraga M, Bastida R, Huson D, Nieselt K, Young D, Parkhill J, Buikstra JE, Gagneux S, Stone 
AC, Krause J (2014) Pre-Columbian mycobacterial genomes reveal seals as a source of New World human tuberculosis. Nature 514:494

Brook CE, Dobson AP (2015) Bats as 'special' reservoirs for emerging zoonotic pathogens. Trends Microbiol 23:172

Chan BK, Turner PE, Kim S, Mojibian HR, Elefteriades JA, Narayan D (2018) Phage treatment of an aortic graft infected with Pseudomonas aeruginosa. Evol Med Public Health 2018:60

Coakley G, Buck AH, Maizels RM (2016) Host parasite communications-messages from helminths for the immune system Parasite communication and cell-cell interactions. Mol Biochem Parasitol 208:33

Corbett S, Courtiol A, Lummaa V, Moorad J, Stearns S (2018) The transition to modernity and chronic disease: mismatch and natural selection. Nat Rev Genet 391:1

Crow JF (2000a) A new study challenges the current belief of a high human male:female mutation ratio. Trends Genet 16:525

Crow JF (2000b) The origins, patterns and implications of human spontaneous mutation. Nat Rev Genet 1:40

Crow JF (2012) Upsetting the dogma: germline selection in human males. PLoS Genet 8:e1002535

Cui J, Li F, Shi Z-L (2019) Origin and evolution of pathogenic coronaviruses. Nat Rev Microbiol 17:181

Cunningham JJ, Brown JS, Gatenby RA, Staňková K (2018) Optimal control to develop therapeutic strategies for metastatic castrate resistant prostate cancer. J Theor Biol 459:67

D'Souza AW, Wagner GP (2014) Malignant Cancer and Invasive Placentation: a case for positive pleiotropy between endometrial and malignancy phenotypes. Evol Med Public Health 2014:136

Dudas G, Carvalho LM, Bedford T, Tatem AJ, Baele G, Faria NR, Park DJ, Ladner JT, Arias A, Asogun D, Bielejec F, Caddy SL, Cotten M, D’Ambrozio J, Dellicour S, Di Caro A, Diclaro JW, Duraffour S, Elmore MJ, Fakoli LS, Faye O, Gilbert ML, Gevao SM, Gire S, Gladden-Young A, Gnirke A, Goba A, Grant DS, Haagmans BL, Hiscox JA, Jah U, Kugelman JR, Liu D, Lu J, Malboeuf CM, Mate S, Matthews DA, Matranga CB, Meredith LW, Qu J, Quick J, Pas SD, Phan MVT, Pollakis G, Reusken CB, Sanchez-Lockhart M, Schaffner SF, Schieffelin JS, Sealfon RS, Simon-Loriere E, Smits SL, Stoecker K, Thorne L, Tobin EA, Vandi MA, Watson SJ, West K, Whitmer S, Wiley MR, Winnicki SM, Wohl S, Wölfel R, Yozwiak NL, Andersen KG, Blyden SO, Bolay F, Carroll MW, Dahn B, Diallo B, Formenty P, Fraser C, Gao GF, Garry RF, Goodfellow I, Günther S, Happi CT, Holmes EC, Kargbo B, Keita S, Kellam P, Koopmans MPG, Kuhn JH, Loman NJ, Magassouba N, Naidoo D, Nichol ST, Nyenswah T, Palacios G, Pybus OG, Sabeti PC, Sall A, Ströher U, Wurie I, Suchard MA, Lemey P, Rambaut A (2017) Virus genomes reveal factors that spread and sustained the Ebola epidemic. Nature 544:309

Ellison PT, Ottinger MA (2014) In: Weinstein M, Lane MA (eds) Sociality, hierarchy, health: comparative biodemography: papers from a workshop, pp. 315-338

Ferretti C, Bruni L, Dangles-Marie V, Pecking AP, Bellet D (2007) Molecular circuits shared by placental and cancer cells, and their implications in the proliferative, invasive and migratory capacities of trophoblasts. Hum Reprod Update 13:121

Gagneux S (2018) Ecology and evolution of Mycobacterium tuberculosis. Nat Rev Microbiol 16:202

Gatenby R, Brown J (2018) The evolution and ecology of resistance in cancer therapy. Cold Spring Harb Perspect Med 8:a033415

Gatenby RA, Silva AS, Gillies RJ, Frieden BR (2009) Adaptive therapy. Can Res 69:4894

Gupta K, Afzal J, Maziarz JD, Hamidzadeh A, Liang C, Erkenbrack EM, Nam H, Haeger J-D, Pfarrer C, Hoang T, Ott T, Spencer T, Pavlicev M, Antczak D, Levchenko A, Wagner GP (2019) The evolution of placental invasion and cancer metastasis are causally linked. bioRxiv: 1
Hawkes K, O’Connell JF, Jones N, Alvarez H, Charnov EL (1998) Grandmothering, menopause, and the evolution of human life histories. Proc Natl Acad Sci USA 95:1336

Holmes EC, Dudas G, Rambaut A, Andersen KG (2016) The evolution of Ebola virus: insights from the 2013-2016 epidemic. Nature 538:193

Hong WS, Shpak M, Townsend JP (2015) Inferring the origin of metastases from cancer phylogenies. Can Res 75:4021

Jault P, Leclerc T, Jennes S, Pirnay JP, Que Y-A, Resch G, Rousseau AF, Ravat F, Carsin H, Le Floch R, Schaal JV, Soler C, Fevre C, Arnaud I, Bretaudeau L, Gabard J (2019) Efficacy and tolerability of a cocktail of bacteriophages to treat burn wounds infected by Pseudomonas aeruginosa (PhagoBurn): a randomised, controlled, double-blind phase 1/2 trial. Lancet Infect Dis 19:35

Jennes S, Merabishvili M, Soentjens P, Pang KW, Rose T, Keersebilck E, Soete O, François P-M, Teodorescu S, Verween G, Verbeken G, De Vos D, Pirnay JP (2017) Use of bacteriophages in the treatment of colistin-only-sensitive Pseudomonas aeruginosa septicaemia in a patient with acute kidney injury-a case report. Crit Care (Lond Engl) 21:129

Kahl J, Brattig N, Liebau E (2018) The untapped pharmacopeic potential of helminths. Trends Parasitol 34:828

Kakasis A, Panitsa G (2019) Bacteriophage therapy as an alternative treatment for human infections. A comprehensive review. Int J Antimicrob Agents 53:16

Kang H-J, Feng Z, Sun Y, Atwal G, Murphy ME, Rebbeck TR, Rosenwaks Z, Levine AJ, Hu W (2009) Single-nucleotide polymorphisms in the p53 pathway regulate fertility in humans. Proc Natl Acad Sci USA 106:9761

Kerr JB, Myers M, Anderson RA (2013) The dynamics of the primordial follicle reserve. Reproduction 146:R205

Kozlowski J, Stearns SC (1989) Hypotheses for the production of excess zygotes: models of bet-hedging and selective abortion. Evolution 43:1369

Liu Z-Y, Shi W-F, Qin C-F (2019) The evolution of Zika virus from Asia to the Americas. Nat Rev Microbiol 17:131

Naxerova K, Jain RK (2015) Using tumour phylogenetics to identify the roots of metastasis in humans. Nat Rev Clin Oncol 12:258

Qiao H, Rao HBDP, Yun Y, Sandhu S, Fong JH, Sapre M, Nguyen M, Tham A, Van BW, Chng TYH, Lee A, Hunter N (2018) Impeding DNA break repair enables oocyte quality control. Mol Cell 72:211

Rook GAW (2012) Hygiene hypothesis and autoimmune diseases. Clin Rev Allergy Immunol 42:5

Sharp PM, Hahn BH (2010) The evolution of HIV-1 and the origin of AIDS. Philos Trans R Soc B 365:2487

Silva AS, Kam Y, Khin ZP, Minton SE, Gillies RJ, Gatenby RA (2012) Evolutionary approaches to prolong progression-free survival in breast cancer. Can Res 72:6362

Smith KR, Hanson HA, Buys SS (2011) Effects of BRCA1 and BRCA2 mutations on female fertility. Proc Biol Sci R Soc 279:1389

Stearns SC, Ebert D (2001) Evolution in health and disease: work in progress. Q Rev Biol 76:417

Stearns SC, Medzhitov R (2015) Evolutionary medicine. Sinauer, Sunderland

Stearns SC, Govindaraju DR, Ewbank D, Byars SG (2012) Constraints on the coevolution of contemporary human males and females. Proc R Soc B 279:4836

Strassmann BI, Garrard WM (2011) Alternatives to the grandmother hypothesis. Hum Nat 22:201

Taubenberger JK, Morens DM (2006) 1918 Influenza: the mother of all pandemics. Emerg Infect Dis 12:15

Tuppi M, Kehrloesser S, Coutandin DW, Rossi V, Luh LM, Strubel A, Hoette K, Hoffmeister M, Schaefer B, De Oliveira T, Greten F, Stelzer EHK, Knapp S, De Felici M, Behrends C, Klinger FG, Doetsch V (2018) Oocyte DNA damage quality control requires 
consecutive interplay of CHK2 and CK1 to activate p63. Nat Struct Mol Biol 25:261

Varyani F, Fleming JO, Maizels RM (2017) Helminths in the gastrointestinal tract as modulators of immunity and pathology. Am J Physiol Gastrointest Liver Physiol 312:G537

Voskarides K (2018) Combination of 247 genome-wide association studies reveals high cancer risk as a result of evolutionary adaptation. Mol Biol Evol 35:473

Weill F-X, Domman D, Njamkepo E, Almesbahi AA, Naji M, Nasher SS, Rakesh A, Assiri AM, Sharma NC, Kariuki S, Pourshafie MR, Rauzier J, Abubakar A, Carter JY, Wamala JF, Seguin C, Bouchier C, Malliavin T, Bakhshi B, Abulmaali HHN, Kumar D, Njoroge SM, Malik MR, Kiiru J, Luquero FJ, Azman AS, Ramamurthy T, Thomson NR, Quilici M-L (2019) Genomic insights into the 2016-2017 cholera epidemic in Yemen. Nature 565:230

Worobey M, Han G-Z, Rambaut A (2014) Genesis and pathogenesis of the 1918 pandemic H1N1 influenza A virus. Proc Natl Acad Sci USA 111:201324197
Worobey M, Watts TD, McKay RA, Suchard MA, Granade T, Teuwen DE, Koblin BA, Heneine W, Lemey P, Jaffe HW (2016) 1970s and 'Patient 0'; HIV-1 genomes illuminate early HIV/AIDS history in North America. Nature 539:98

Yachida S, Jones S, Bozic I, Antal T, Leary R, Fu B, Kamiyama M, Hruban RH, Eshleman JR, Nowak MA, Velculescu VE, Kinzler KW, Vogelstein B, Iacobuzio-Donahue CA (2010) Distant metastasis occurs late during the genetic evolution of pancreatic cancer. Nature 467:1114

Zhao Z-M, Zhao B, Bai Y, Iamarino A, Gaffney SG, Schlessinger J, Lifton RP, Rimm DL, Townsend JP (2016) Early and multiple origins of metastatic lineages within primary tumors. Proc Natl Acad Sci USA 113:2140 